\title{
Maternal and Fetal Outcome of Prelabor Rupture of Membranes at Expectant Management
}

\author{
T WASIM S NAJIBULLAH \\ Department Of Gynaecology \& Obstetrics, Services Hospital, Lahore \\ Correspondence to Dr. Tayyiba Wasim,
}

\begin{abstract}
This descriptive study was carried out to analyze the maternal and fetal outcome of 24 hours expectant manage in patients of PROM at term. 100 women presenting with prelabor rupture of membranes at term were inc All the patients were managed conservatively for 24 hours, followed by induction if labor did not spontaneously, or if signs of chorioamnionitis developed at any stage. Magnitude of PROM during the year 2002 $7.008 \%$. Spontaneous labor rate with in 24 hours was $84 \% .2 \%$ patients developed signs of chorioamnionitis in than 24 hours and $14 \%$ patient did not enter into spontaneous labor after 24 hours of PROM. $94 \%$ patients PROM delivered vaginally while 6 caesarian sections were carried out. Postnatal complications were observe $17 \%$ of patients. These included chorioamnionitis $2 \%$, PPH $7 \%$, puerperal pyrexia $4 \%$, wound infection $3 \%$, DVT in 1\% patient. Mean Apgar score of babies was 5.90, 1min after birth and 8.7, 5 min after birth. Maxin babies had apgar score of 9 at 5 min after birth, 8 babies were admitted to ICU and only 1 baby developed pro neonatal infection. This study shows that conservative management is safe with excellent maternal and neon outcome.
\end{abstract}

Key words: Term, pre labor rupture of membrane

PROM is rupture of membranes prior to the onset of labor at or beyond 37 weeks gestation ${ }^{1}$. About $10 \%$ of all gestations are complicated by $\mathrm{PROM}^{2} .80 \%$ of PROM cases go into spontaneous labor within 24 hours $^{3}$. Management of PROM is either induction of labor or expectant. Expectant management carries a risk of infection when induction is delayed for more than 24 hours while there is risk of failed induction and operative delivery if induction is attempted too soon ${ }^{4,5,6}$.

In this study expectant management was adopted for 24 hours followed by induction if labor did not start spontaneously or if signs of chorioamnionitis developed at any stage.

Purpose of study was to analyze the maternal and fetal outcome of 24 hours expectant management in patients of PROM at term and to find out that this regimen does decrease maternal morbidity without increasing the chances of fetal morbidity and mortality.

\section{Subjects and methods}

It was a prospective descriptive study carried out at gynae unit1 of Services Hospital, over one year period. 100 women fulfilling the inclusion criteria were selected by convenient sampling. All the patients were subjected to conservative management for 24 hours after counseling.

Inclusion Criteria were:

1. Singleton pregnancy, Gestational age 37-42weeks, Cephalic presentation, PROM,

2. Reactive cardiotocography and no other contraindication to vaginal delivery.

The patients in active labor or with fetal distress at the time of admission were excluded, so also were those with signs of chorioamnionitis, cephalopelvic disproportion, medical illnesses like diabetes, cardiac disease, hypertension and chronic renal and airway diseas multiple pregnancies and previous history of instrument delivery or caesarian section.

Digital examination was avoided and PROM wa confirmed by sterile speculum examination. Complete blood and urine examinations were sent as baseline Vaginal swabs were sent for culture and sensitivity and antibiotic cover was given with injection cefatexime 1 gram I.V. at 12 hourly intervals.

Patients were monitored for their pulse, temperature, color and odor of liquor on pad and uterine tenderness.

If labor did not start spontaneously in 24 hours or if there was any sign of chorioamnionitis, labor was induced after Bishop scoring. If Bishop score was 5 or $<5$, ripening and induction was done by insertion of prostaglandin $E_{2}$ pessary, and repeated if needed. If Bishop score was greater than 5 , induction was done with oxytocin infusion.

Augmentation of labor was done when needed.

Maternal outcome was determined by failure of labor to start spontaneously, poor bishop score after 24 hours of PROM, failure of induction, development of chorioamnionitis, caesarian section, postnatal complications e.g. postpartum hemorrhage and pyrexia, offensive vaginal discharge and thromboembolism.

Poor fetal outcome was determined by low Apgar score at $5 \mathrm{~min}$, signs of asphyxia, prolonged tachypnoea, tachycardia and a dmission to neonatal intensive $\mathrm{c}$ are u nit for sepsis, hyperpyrexia or hypothermia.

\section{Results}

The study extended over a period of 1 year from Jan to Dec 2002. There were 3724 deliveries during this period. Out of these, 261patients were admitted with PROM, giving it a magnitude of $7.008 \%$. Out of the 100 - selected 
patients, 50 were primigrvida and 50 multigravida. Difference of clinical characteristics was observed in both groups.

Table-1 Clinical characteristics of prom patients

\begin{tabular}{lll}
\hline $\begin{array}{l}\text { Clinical characteristic } \\
\text { (Mean value) }\end{array}$ & Nullipara & Multipara \\
\hline Age & 26.2 years & 28.7 years \\
Gestational age & 38.46 weeks & 38.14 weeks \\
Bishop score & 4.857 & 5 \\
PROM to active labor interval & 18.75 hours & 13.8 hours \\
PROM to delivery interval & 27.36 hours & 23.04 hours \\
\hline
\end{tabular}

Majority of the patients were between 26-30 years of age. Nullipara's were more in younger age group. The youngest patient who presented with PROM was 19 years and oldest was 36 years of age. In nullipara mean gestational age of PROM was 38.46 weeks where as in multipara it was 38.14 weeks.

$84 \mathrm{p}$ atients had onset of a ctive labor spontaneously. Only 14 patients required induction of labor due to failure of conservative management and 2 patients due to chorioamnionitis. Majority of patients had bishop score of 6. In 14 patients active labor started by induction in the next 12 hours while in 2 patients, induction failed.

The shortest prom to delivery interval was 9 hours. PROM to delivery interval was delayed to 24-36 hours in most nullipara. The mean PROM to delivery interval was significantly shorter in multipara than nullipara

\section{Maternal outcome}

Table-2 Parameters of maternal outcome before delivery

\begin{tabular}{lll}
\hline Variable & Nullipara & Multipara \\
\hline Spontanious labor & $43 \%$ & $41 \%$ \\
Induction to active labor & 6.6 hours & 3 hours \\
interval & & \\
$1^{\text {st }}$ stage & 9.2667 hours & 7.204 hours \\
$2^{\text {nd }}$ stage & $35.67 \mathrm{~min}$ & $24.18 \mathrm{~min}$ \\
$3^{\text {rd }}$ stage & $10 \mathrm{~min}$ & $8 \mathrm{~min}$ \\
\hline
\end{tabular}

The results also showed that more nullipara entered into spontanious labor than multipara. L abor s tarted e arlier in multipara as compared to nullipara while Ist stage of labor was longer in nullipara. The difference of duration was statistically significant.

Majority of patients took $30 \mathrm{~min}$ in second stage of labor. 3rd stage of labor was managed actively and $88 \%$ patients delivered in $1^{\text {st }} 15 \mathrm{~min}$.

Table 3 Mode of delivery

\begin{tabular}{llll}
\hline Mode of delivery & Nullipara & Multipara & Total \\
\hline Vaginal delivery & 45 & 49 & 94 \\
SVD & 34 & 45 & 79 \\
Forceps & 11 & 4 & 15 \\
c $s$ & 5 & 1 & 6 \\
\hline
\end{tabular}

Among the 100 patients admitted with PROM, 94\% had vaginal deliveries whereas $6 \%$ were delivered by $\mathrm{c} / \mathrm{s}$. Of the 94 vaginal deliveries, $79 \%$ were SVD, $15 \%$ were forceps deliveries, which were applied due to prolonged $2^{\text {nd }}$ stage and fetal distress. Nullipara had a higher rate for operative deliveries than multipara.

Table-4 Maternal complications

\begin{tabular}{|c|c|c|c|c|}
\hline $\begin{array}{l}\text { Maternal } \\
\text { complications }\end{array}$ & No & $\begin{array}{l}\text { Induction } \\
\text { with } \\
\text { oxytocin }\end{array}$ & $\begin{array}{l}\text { Induction } \\
\text { with } \mathrm{PgE}_{2}\end{array}$ & $\begin{array}{l}\text { Induction } \\
\text { with } \mathrm{PGE}_{2} \\
\text { followed } \\
\text { by oxytocin }\end{array}$ \\
\hline $\begin{array}{l}\text { Chorioamnio- } \\
\text { nitis }\end{array}$ & 2 & 2 & 0 & 0 \\
\hline PPH & 7 & 1 & 4 & 2 \\
\hline $\begin{array}{l}\text { Puerperal } \\
\text { pyrexia a }\end{array}$ & 4 & 0 & 2 & 2 \\
\hline $\begin{array}{l}\text { Wound } \\
\text { infection }\end{array}$ & 3 & 0 & 2 & 1 \\
\hline DVT & 1 & 0 & 1 & 0 \\
\hline
\end{tabular}

Maternal complications developed in 17 patients, 2 of them had chorioamnionitis for which they were induced but they developed fetal distress and c/s was performed. Postoperatively both of these patients developed wound infection and one of them ended up with DVT.

Table-5 Fetal outcome

\begin{tabular}{lll}
\hline Variable & Nullipara & Multipara \\
\hline A/s at $1 \mathrm{~min}$ & 5.18 & 6.02 \\
A/s at $5 \mathrm{~min}$ & 8.66 & 8.74 \\
Admission to ICU & 5 & 3 \\
Neonatal infection & 1 & 0 \\
\hline
\end{tabular}

Mean Apgar score of babies one min after birth was 5.90. None of the babies had Apgar score less than 4 while maximum patients had Apgar score of 7 .

Mean apgar score 5 min after birth was 8.7. None of the babies had apgar score less than 6 at $5 \mathrm{~min}$ after birth. Maximum babies had Apgar score of 9 .

8 babies were admitted to ICU. Babies with $\mathrm{c} / \mathrm{s}$ had presenting complaints of transient bradicardia (1), tachycardia and hypothermia (1), and low Apgar score (1). Two babies with forceps deliveries were admitted to ICU. Their indications of a dmission were meconium aspiration (1), and hyperthermia (1). Three patients delivered by SVD were admitted to ICU. They had low Apgar score (1), transient bradicardia (1), while one of the babies delivered with apnea had to be incubated. Blood cultures of all the babies admitted in ICU were sent, only 1 had growth of staph aureus.

\section{Discussion}

The magnitude of PROM in this study was 7.008, which is higher than Nasira's study of $5.3 \%$ but lower than $10.0 \%$. of Rathmer and $12.9 \%$ of Ladfors studies ${ }^{7.8}$. The attendance of women at antenatal clinic provides information about PROM and accurate dating of gestation by early ultrasound scanning. Only $28 \%$ of patients in this study were booked.

Only $16 \%$ of patients in this study did not go into spontaneous labor after 24 hours of rupture of membranes. 
This is almost comparable to $20 \%$ or $23 \%$ reported by other studies, and the slight difference may be due to the fact that only nullipara were included in the study by $\mathrm{H}$. Cammu, as more multipara go into spontaneous labor after PROM as compared to nullipara.

Secondly, the difference may be due to criteria used to define PROM, as in our study PROM was onset of labor at any time after the patient presented with PROM while in H Cammu study the only patients who were not in labor within the $1^{\text {st }} 6$ hours after PROM were taken into account.thus explaining the lower incidence of spontanious labor in that study ${ }^{7,9}$.

Mean Bishop score in our study group was 4.93 as compared to 2.6 in actively managed group of Nasira Tasneem. High bishop score in our study is in accordance with the hypothesis that conservative management for 24 hours results in improvement of Bishop score at the time of induction.

The Mean duration of $1^{\text {st }}$ stage by conservative management in our study was longer than studies of active management. This difference becomes insignificant when we take into account the cost, staff involved and intensive fetal heart rate monitoring required for induction of labor. The duration of 2 nd and $3 \mathrm{rd}$ stage in comparison to study of Dr. Nasira's is shorter in actively managed group but comparable to our study in conservative group, while in $\mathrm{H}$ Cammu group duration in both active and conservative group is longer than our study group. This difference may be due to the a ctive management of $2^{\text {nd }}$ stage of labor in our study group.

The interval between induction and active labor onset is shorter in our study as compared to the national and international s tudy in which no c onservative management was done and bishop scores are poor at the time of induction. This is again in accordance with the postulation that conservative management helps in ripening the cervix by release of natural prostaglandins at the site of rupture of membranes ${ }^{7,10,11,13}$. C/S rate, and hence maternal morbidity, was significantly lower in subjects of our study as compared to the studies with immediate induction.

Maternal pyrexia occurred only in 4 patients, which is much lower than active management groups of Nasira and $\mathrm{H} \mathrm{Cammu}$. The increase in maternal pyrexia in active group may be due to increased digital examinations before delivery. This shows that conservative management is not only beneficial to decrease the incidence of $\mathrm{c} / \mathrm{s}$ but it is also successful to decrease the incidence of maternal pyrexia.

Neonatal infections were also significantly less as compared to Nasira and $\mathrm{H}$ Cammu studies. This may be due to reduced No of digital examinations and prophylactic antibiotic cover ${ }^{4.12}$. In our study 3 babies had mild pyrexia for 24 hours after delivery while only one baby born by c/s due to chorioamnionitis developed signs of neonatal sepsis. Fortunately there was no perinatal and maternal death.

\section{Conclusion}

Conservative management of PROM did not negatively effect maternal and fetal outcome It allows majority of women to go into spontanious labor and improves Bishop score in rest of the patients resulting in better response to induction and decrease in No of $\mathrm{c} / \mathrm{s}$ thus reducing maternal morbidity. There is also decrease in newborn infection rate and admission to ICU thus reducing infant morbidity and mortality.

\section{References}

1. Alexander JM, Cox SM. Clinical course of premature rupture of membranes. Semen Perinatol 199; 20:369-74

2. Duff P, Huff RW, Gibbs RS: Management of premature rupture of membranes and unfavorable cervix in term pregnancy. Obstet Gynecol 1984; 63:697-702I

3. Hjertberg R, Hammerstorm M, Moberger B, Nordlander E, Granstrom L. Premature rupture of the membranes (PROM) at term in nulliparous women with a ripe_cervix. A randomized trial of 12 or 24 hrs of expectant management. Acta Obs Gynae Scand 1996;75:48 -53

4. Seaward PG, Hannah ME, Myhr TL, Farine D, Ohlsson A, Wang EE et al. International multicentre term PROM study: evaluation of predictors of neonatal infection is infants born to patients with premature rupture of membranes at term.Am J Obstet Gynaecol 1998 Sep; 179: 635 - 9

5. Ngai SW, Chan YM, Lam SW, Lao TT. Labor Characteristics and uterine activity; misoprostol compared with oxytocin in women at term with prelabor rupture of membranes. Br J Obstet Gynaecol 2000; 107:222-7

6. Hannah ME, Hodnett ED, Willan A: Prelabor rupture of the membranes at term: expectant management at home or in hospital? The TermPROM Study Group. Obstet Gynecol 2000 Oct; 96(4): 533-8[Medline].

7. Tasnim Nasira.Spontaneous prelabor rupture of membranes at term.Pakistan J MED RES.Jun2000;39:66-9

8. Ladfors L, Mattsson LA, Eriksson M, Fall O. Is a speculum examination sufficient for excluding the diagnosis of ruptured fetal membranes Acta Obstet Gynecol Scand 1997 Sep;76(8):739-742

9. H Cammu, H Verlaenen et al. PROM in term women. Am J Obst Gynaecol. Oct 1990;4:(76):671-74.

10. Rizvi R, Rizvi F.induction and augumentation of labour, use of dinoprostone E2 for u nripe cervix in private sector. The professional. 1998; 5(4): $505-512$.

11. Riaz SG, Saeed F.A comparative study of vaginal prostaglandine 2 pessary with intravenous oxytocin for the induction of labor after spontanious rupture of.membranes.Specialist. 1992;9:63-67

12. Mercer BM, Miodovnik $\mathrm{M}$ et al. Antibiotic therapy for reduction of infant morbidity after preterm rupture of membranes. JAMA 1997 Sep 24; 278(12):989-95.

13. Rather L, Scheidel $P$ etal. Premature rupture of fetal membranes at term. Sequelae of conservative management. Z Geburtshiffe Neonatol. 2000 Mar - Apr; 204: 43-48.. 